\title{
GIANT EXTRAPLACENTAL CHORANGIOMA: A CASE REPORT AND REVIEW.
}

Dr. Adil S. A. K, Dr. Shilpa K, Dr Bharthi M, Dr Anubha A.

1. Assistant Professor, Department of Pathology, Mysore Medical College and Research Institute, Mysore.

2. Associate Professor, Department of Pathology, Mysore Medical College and Research Institute, Mysore.

3. Professor, Department of Pathology, Mysore Medical College and Research Institute, Mysore.

4. Post Graduate Student, Department of Pathology, Mysore Medical College and Research Institute, Mysore.

\section{CORRESPONDING AUTHOR}

Dr. S. A. K. Adil, Assistant Professor, $\# 259$, $5^{\text {th }}$ Main, Bannimantap, 'C' Layout, Mysore -570015 .

E-mail: saka291@yahoo.co.in,

Ph: 919019691259.

ABSTRACT: Chorangioma or placental hemangioma is a primary benign neoplasm of the placenta. It consists of vascular mass arising from chorionic tissue. Chorangiomas provide useful insights into pathophysiology and pathogenesis of fetal and maternal disorders .We herewith, present a case of giant extraplacental chorangioma associated with maternal preeclampsia and low birth weight baby.

KEYWORDS: Placenta, pathophysiology, chorangioma.

INTRODUCTION: Chorangioma is a non-trophoblastic tumor of the placenta, characterised by excessive vascular proliferation within chorionic villi. It is also referred to as a hamartoma or a hyperplastic capillary lesion. Though a benign lesion, large chorangiomas are usually associated with maternal or foetal complications. Small intraplacental chorangiomas are common but large extraplacental chorangiomas are quite rare. Only, few similar cases are reported in literature.

CASE HISTORY: A 26 year old female, $\mathrm{G}_{2} \mathrm{P}_{1} \mathrm{l}_{1}$ at 36 weeks of gestation was admitted for preeclampsia and emergency cesarean section was done. A live female baby of $2 \mathrm{~kg}$ was extracted. Postpartum course for both baby and mother was uneventful.

PATHOLOGICAL FINDINGS: Gross examination, showed a lobulated firm mass attached to the placenta by a short pedicle, measuring $13 \times 8 \times 4 \mathrm{cms}$. (Fig 1) The pedicle was cut and the whole soft tissue mass weighed 300 gms .Placenta, membranes and umbilical cord were unremarkable. Cut section from the mass showed grey-white to grey-tan areas. Microscopic examination revealed a lesion composed of capillary-type blood vessels within a cellular stroma, showing occasional mitosis (Fig 2, Fig 3,Fig 4). Few cavernous spaces were also interspersed. The histological features were consistent with chorangioma.

DISCUSSION: The incidence of large chorangiomas range from 1:3500 to 1:9000.1The occurrence increases in placentas at high altitudes. ${ }^{2}$ They are often found in primipara and twin pregnancies. Risk factors associated with the occurrence of chorangiomas include women over 30 years, diabetes and hypertension. The recurrence risk is not yet known. Examination of the placenta is essential, as the presence of chorangioma helps in elucidation of specific etiologies of 
abnormal pregnancies. The histological diagnosis of a chorangioma is not a problem. Variants include capillary, cavernous, endotheliomatous, fibrosing and fibromatous chorangiomas.

In this study, the lesion was surrounded by a layer of trophoblast and composed of small size capillary vessels lined by single layer of flattened endothelial cells. There was no evidence of atypia. Few cellular areas in the lesion showed 3 mitosis per 10 high-power fields .If the mitotic count is more than 7 per 10 high-power fields and associated with cytologic atypia and necrosis it is termed as atypical chorangioma. ${ }^{3}$ Chorangiocarcinoma, though a misnomer, is considered if there is trophoblast proliferation. ${ }^{4}$

As the lesion involved the stem villi and was expansile, it was distinguished from chorangiosis and chorangiomatosis. In chorangiosis, terminal villi are involved and a minimum of 10 villi are required, each with 10 or more vascular channels ${ }^{5}$ and in chorangiomatosis lesion permeates the normal villi instead of an expansile lesion. ${ }^{6}$ The diagnosis of chorangiomas is problematic, if it undergoes infarction or shows degenerative changes such as hyalinization, myxoid stromal changes or calcification.

Chorangioma is a potentially hazardous vascular lesion. It is clinically significant if the size is greater than $5 \mathrm{cms}$, which is then referred to as a giant chorangioma. ${ }^{7}$ Extensive literature review, reveals a distinct relationship between chorangiomas and feto-maternal complications, which include, fetal cardiomegaly, fetal anemia, thrombocytopenia, polyhydramnios, nonimmune hydrops, fetal heart failure, fetal growth restriction, preterm delivery.1,2,6.7,8,9,

Few authors have reported its association with maternal preeclampsia, which was apparent in this case.1, 2 Fetal growth restriction is a cause of low birth weight, its relation to chorangioma has been documented in earlier studies.1, 2, 7, 9.Chorangioma, acts as a physiological dead space, resulting in chronic hypoxia leading on to fetal growth restriction. ${ }^{7}$ This explains, the low birth weight in this infant. Though, in our study it was a giant chorangioma many of the complications were not observed. It is speculated, that placental tissue compensates for the foetal demands, thus decreasing the incidence of complications. Earlier studies have described the pathophysiology and pathogenesis of various complications associated with chorangioma. ${ }^{1}$ 2,7 Pathophysiologically, fetal heart failure can arise from increased blood flow through the low resistance vascular channels, fetal anemia and thrombocytopenia may occur due to sequestration of blood in the vascular mass $^{7}$ and hydrops fetalis may result from microangiopathic haemolytic anaemia. ${ }^{8}$ 9. Other complications include, Polyhydramnios which may be related to fetal heart failure ${ }^{7}$ and Ante partum haemorrhage, resulting from rupture of vascular pedicle. ${ }^{10}$ Therefore, chorangiomas cannot be overlooked as they have a significant impact and can result in serious problems for the developing fetus and the mother. Literature search reveals that MRI, Doppler and ultrasound imaging helps in prenatal diagnosis of chorangiomas ${ }^{11}$ and the different modalities of treatment are intrauterine transfusions through cordocentesis, amniodrainage for polyhydramniosis, endoscopic devascularization, alcoholic ablation and interstitial laser coagulation. ${ }^{12}$

CONCLUSION: Examination of placenta is crucial in complicated pregnancies for identifying chorangiomas. The pathophysiology and pathogenesis of various feto-maternal complications can be accounted by this biologically indolent entity.

Antenatal diagnosis and treatment of placental chorangioma can reduce fetal morbidity and mortality.

Journal of Evolution of Medical and Dental Sciences/Volume1/ Issue4/October- 2012 Page 299 


\section{CASE REPORT}

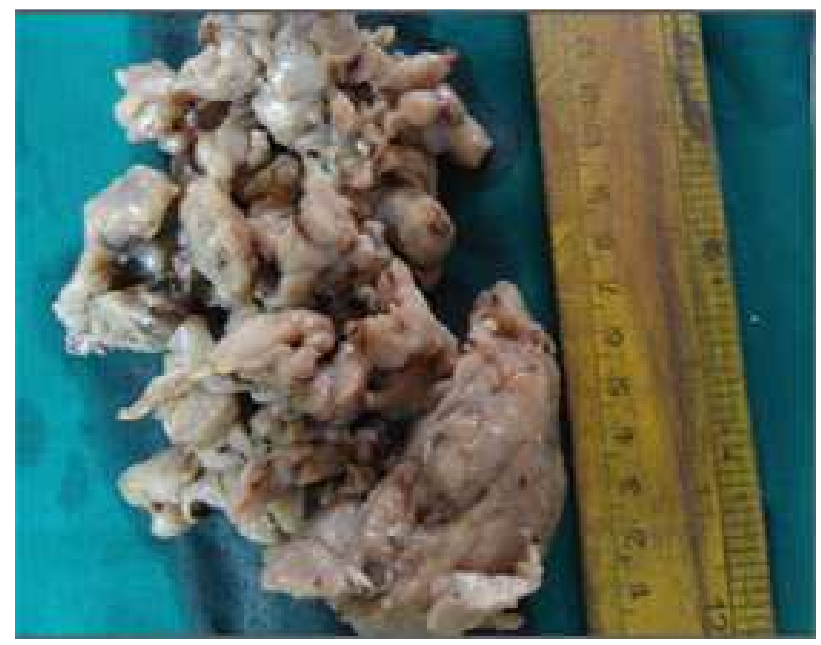

Fig 1-Gross, large lobular, soft tissue mass.

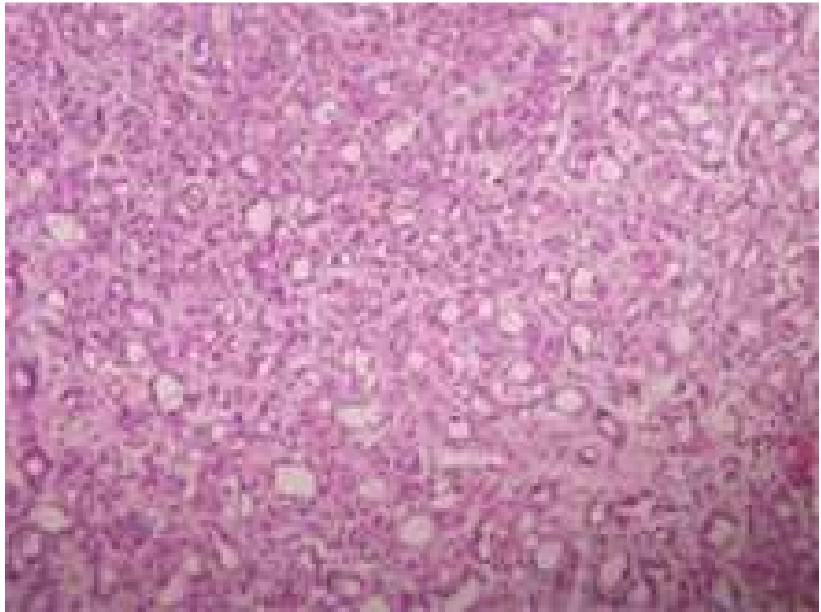

Fig 2-Showing predominantly capillary size vessels within the stroma (H\& E, X 200)

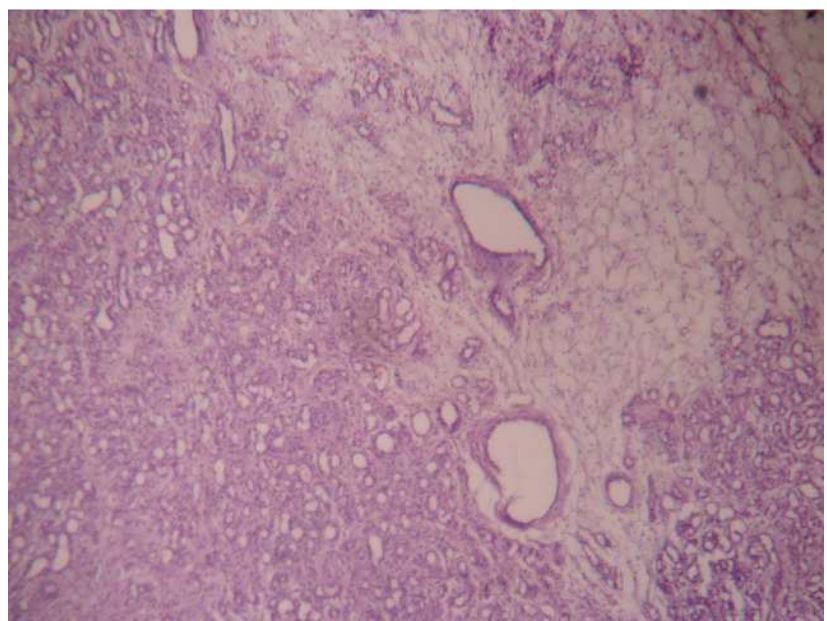

Fig -3 Microphotograph showing varying size vessels within the stroma (H\& E, X 100) 


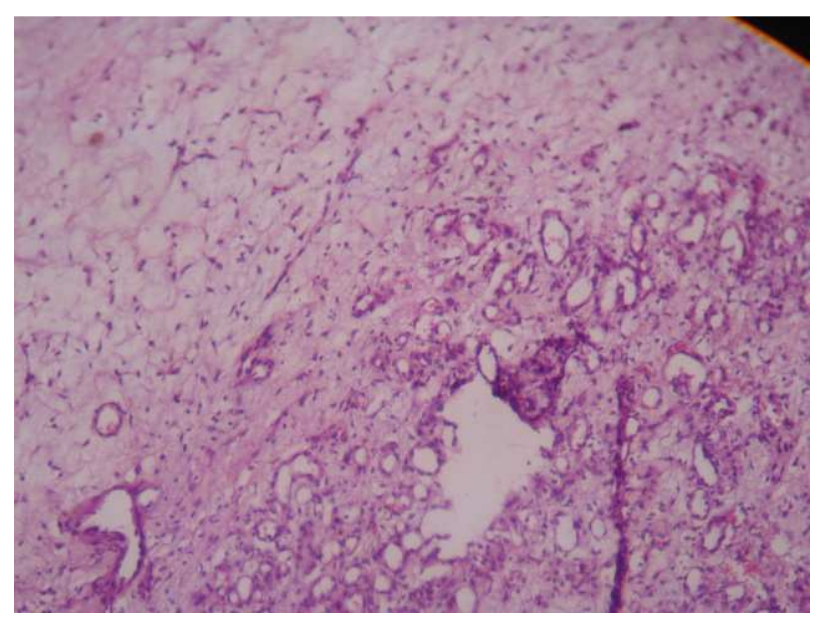

Fig-4 AnotherView showing blood vessels lined by flat endothelial cells (H\& E, X 200)

\section{REFERENCES:}

1. Fox H, Sebire N.J.Non-trophoblastic tumors of the placenta. In: Fox H.Pathology of the placenta.2nd ed.Philadelphia: Saunders Elsevier; 2007. 401-430.

2. Kay H, Nelson DM, Wang Y. The Placenta: From Development to Disease.UK;Wiley- Blackwell;2011:283-284

3. Mesia AF,Mo P,Ylagan LR.Atypical cellular chorangioma.Arch Pathol Lab Med 1999;123(6):536-538

4. Baergan.R.N.Manual of Pathology of the Human placenta. 2ndedition,New York; Springer, 2011.p420-42

5. Altshuler G. Chorangiosis: an important placental sign of neonatal morbidity and mortality. Arch Pathol Lab Med. 1984;108:71-74

6. Ogino S., Redline R. Villous capillary lesions of the placenta: distinctions between chorangioma, chorangiomatosis, and chorangiosis. Hum Pathol. 2000;31(8).945954

7. Stryjak KG, Lesiak MR, Grzegorz H, Reborowicz H.Nontrophoblastic placental tumors. Archives of Perinatal Medicine 2011; 17(2):113-117.

8. Sabhikhi AK,Chaudhury MC, Singh D,Raja LN.Chorangioma of the Placenta with Hydrops Fetalis .J Ind Ped .1996;33:520

9. Zanardini C., Papageorghiou A. Giant placental chorioangioma: natural history and pregnancy outcome. Ultrasound Obstet. Gynecol.2010; 35: 332-336.

10. Tan SA, Yeo SH.Placental Chorangioma: A case report and review. Singapore Med J.1992; 33:83-85.

11. Shafgat G, Iqbal F, Rizvi F.Chorangioma of the Placenta with hydrops Foetalis . JPMA 2009;6:23

12. Lez C,Fures R,Hrgovic Z,Belina S,Fajdic J,Munstedt K.Chorangioma placentae.Rare Tumors. 2010; 2(4): doi: 10.4081/rt.2010.e67 